\title{
Simulation Analysis of Train Disc Brake Temperature Field
}

\author{
Libo Tang \\ Machinery Engineering College \\ Dalian Jiaotong University \\ Dalian,China
}

\author{
Guoshun Wang \\ Machinery Engineering College \\ Dalian Jiaotong University \\ Dalian,China
}

\begin{abstract}
Simulation calculation of temperature field of train disc brake system under $500 \mathrm{r} / \mathrm{min}$ fixed speed condition is carried out by using the software ABAQUS. The result shows: the heat quantity generated by braking firstly forms tailed area using friction radius as center; with continuous development of braking process, annular temperature distribution is formed, and finally, surface temperature area of brake disc displays spotted. The temperature of brake pad rises quickly. When braking begins 2.5 seconds, the temperature reaches extreme. With extension of braking process, surface temperature begins diffusing to peripheral and thickness directions until it ends. The temperature field distribution obtained by simulation calculation of finite element model provides effective reference for design and engineering application of brake disc and brake pad.
\end{abstract}

Keywords- disc brake, temperature field, ABAQUS software, finite element analysi

\section{INTRODUCTION}

Human resistance is applied to moving bodies, which reduces speed or stops moving or keeps original moving state, called braking. The braking process is that train kinetic energy is converted into energy in other form. Uneven temperature field and stress field chronically act on brake, which can cause the generation and expansion of heat crack, and finally braking system fails [1-2]. By simulating and predicting temperature field in friction braking process, the brake has very important meaning for train safety. Lele Zhang [3], .etc use MARC software, ANSYS software, etc., and apply friction power method, etc. to carry out numerical simulation of $160 \mathrm{~km} / \mathrm{h}$ high-speed brake disc $1 / 4$ model. The effect of braking loading way, braking working condition and environmental temperature on transient temperature field of brake disc is discussed. Wenqing Zhao, etc. [4] apply nonlinear finite element analysis software MSC.Patran to obtain transient temperature curve. Haiyan Zhao, etc.[5] proposes that heat flux distribution in surface heat flux has periodicity, Intermittency and attenuation, and brake disc surface transient temperature contacted with brake lining displays saw-toothed variation to form fatigue load spectrum and circulation heat load. ABAQUS finite element analysis software is used to researching temperature distribution regularity of circumferential direction, radius direction and thickness direction of brake disc.

\section{MODEl Establishment AND PARAMETER SETTING}

The model uses circular brake disc. In the model, half of brake disc is taken for analysis, braking lining is composed of multiple cylinders, and the model takes a single cylinder for calculation. In calculation process, suppose brake disc and brake pad are elastic-plastic deformation body. As shown in Figure 1, the model size is shown in Table I.
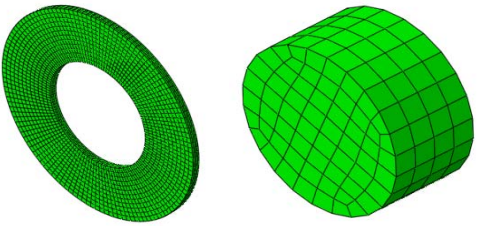

Figure 1. Mesh of brake disc and brake pad

TABLE I. DIMENSIONS OF MODEL

\begin{tabular}{cccc|cc}
\hline \multicolumn{3}{c|}{ Size of brake disc } & \multicolumn{2}{c}{$\begin{array}{c}\text { Size of brake } \\
\text { pad }\end{array}$} \\
\hline Inner & Outer & Friction & depth & Radius & Height \\
radius & radius & radius & 20 & of & of \\
150 & 300 & 225 & & brake & brake \\
& & & & pad & pad \\
& & & & 20 & 20 \\
\hline
\end{tabular}

In simulation process, heat flux distribution adopts heat flux distribution coefficient method, heat flux distribution proportion between brake disc and brake pad is $8: 2$, friction coefficient is obtained by actual measurement method, and friction coefficient of $500 \mathrm{r} / \mathrm{min}$ is 0.41 ; the material of experimental brake disc is H13, the material of brake pad is powder metallurgy material, and the used material parameters are shown in Table II.

TABLE II. MATERIAL PARAMETER

\begin{tabular}{ccc}
\hline & $\begin{array}{c}\text { brake } \\
\text { disc }\end{array}$ & $\begin{array}{c}\text { brake } \\
\text { pad }\end{array}$ \\
\hline Density $(\mathrm{kg} \cdot \mathrm{m}-3)$ & 8000 & 5500 \\
thermal conductivity $(\mathrm{W} \cdot(\mathrm{m} \cdot \mathrm{K})-1)$ & 61 & 74 \\
$\begin{array}{c}\text { specific heat }(\mathrm{kJ} \cdot(\mathrm{kg} \cdot \mathrm{K})-1) \\
\text { thermal expansion coefficient }(/ \mathrm{K}- \\
1)\end{array}$ & $\begin{array}{c}745 \\
\text { 1) }\end{array}$ & 436 \\
\hline
\end{tabular}




\section{Simulation CAlculation Result And Analysis}

\section{A. Variation of disc surface temperature distribution over friction time}

Figures 2 and 3 show different variation of brake disc surface temperature at $0.12 \mathrm{~s}$ and $10 \mathrm{~s}$. As you can see from Figure 2 , in the initial stage of braking, the area rubbed by brake disc surface forms banded area; the temperature of area contacted with brake pad is highest, and the temperature of area which is far away from friction area gradually drops; As you can see from Figure 3, as friction continues, the temperature gradually transmits to the whole brake disc to form annular temperature area; more detailed analysis is carried out below.

\section{1)Variation of disc surface temperature distribution over friction time}

Figures 2 and 3 show different variation of brake disc surface temperature at $0.12 \mathrm{~s}$ and $10 \mathrm{~s}$. As you can see from Figure 2, in the initial stage of braking, the area rubbed by brake disc surface forms banded area; the temperature of area contacted with brake pad is highest, and the temperature of area which is far away from friction area gradually drops; As you can see from Figure 3, as friction continues, the temperature gradually transmits to the whole brake disc to form annular temperature area; more detailed analysis is carried out below.

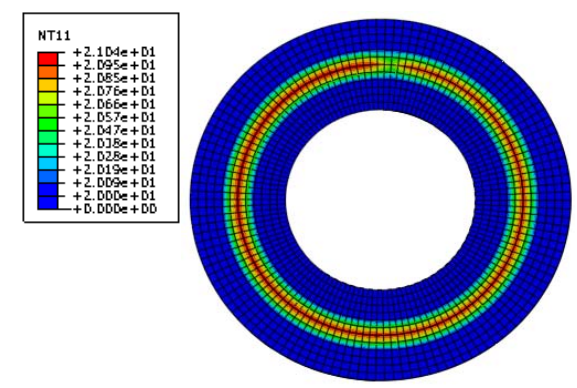

Figure 2. temperature cloud picture of brake disc at 0.12 seconds

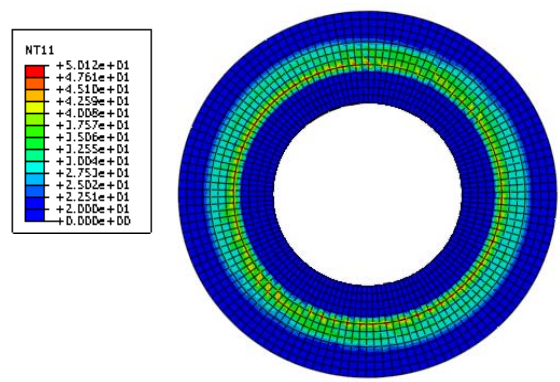

Figure 3. temperature cloud picture of brake disc at 10 seconds
Six points are taken along diameter direction of brake disc, as shown in Figure 4. Point 5 is at $240 \mathrm{~mm}$ on friction radius, and the temperature variation of point 5 within braking time is shown in Figure 5. The temperature curve in the figure displays saw-toothed fluctuation. From start, point 5 keeps environmental temperature. As brake disc rotates, point 5 enters braking friction area, and brake disc fiercely rubs brake pad to generate large amounts of energy. The temperature sharply rises, and thus, point 5 enters friction area once every 0.12 seconds because the rotation period of brake disc is 0.12 seconds. The temperature rises once, the temperature which breaks away from friction area begins dropping, and the process circulates until it ends. When braking time is 2.26 seconds, the temperature of point 5 reaches peak value; subsequently, the absolute temperature of point 5 gradually drops, the highest point of temperature transfers to other points because the temperature of brake disc surface begins even; as extension of braking time, the temperature of point 5 basically keeps unchanged, which indicates that the diffused heat quantity of the point and the obtained heat quantity basically balance. It predicts: if the braking time prolongs, the temperature of point 5 continues rising. Round trip gradually forms the saw-toothed rising process.

The temperature variation curve of six points taken along diameter direction of brake disc is shown in Figure 6. Points 1, 2, 3, 4, 5 and 6 display saw-toothed variation, but because friction radiuses are different, point 5 at friction radius quickly reaches the maximum value of temperature; because brake disc is continuum, the temperature of point 5 is limited by other peripheral points; the temperature drops within short time, the heat quantity transfers around which enables the temperature of peripheral points to quickly rise, and thus, the dynamic balance is reached.

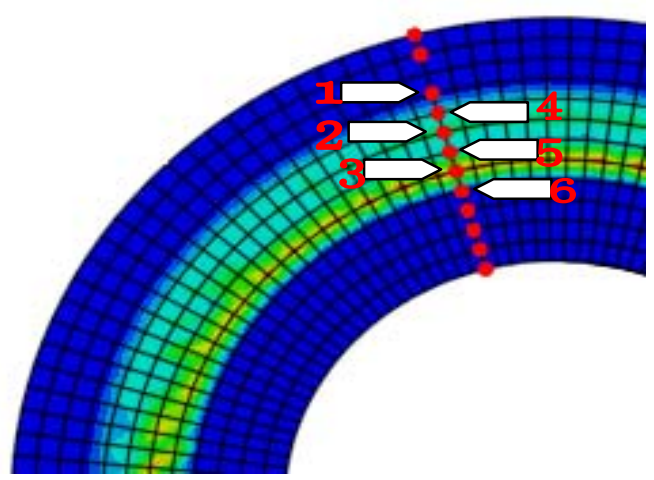

Figure 4. Position of analysis points in brake disc

2) Temperature distribution of radius direction of brake disc 


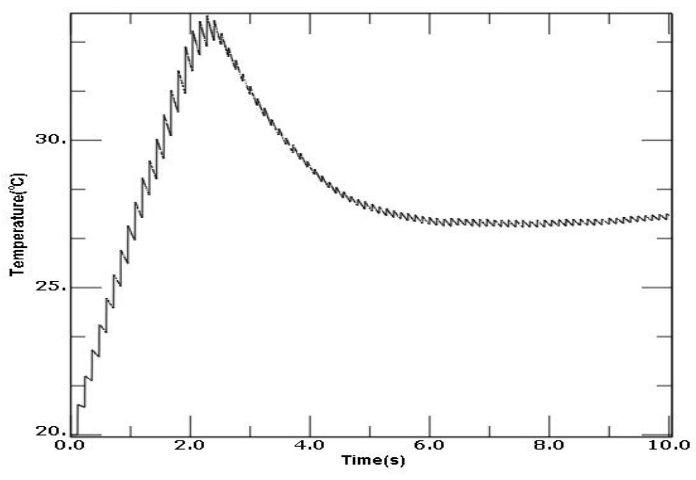

Figure 5. Temperature variation of point 5 in the all time

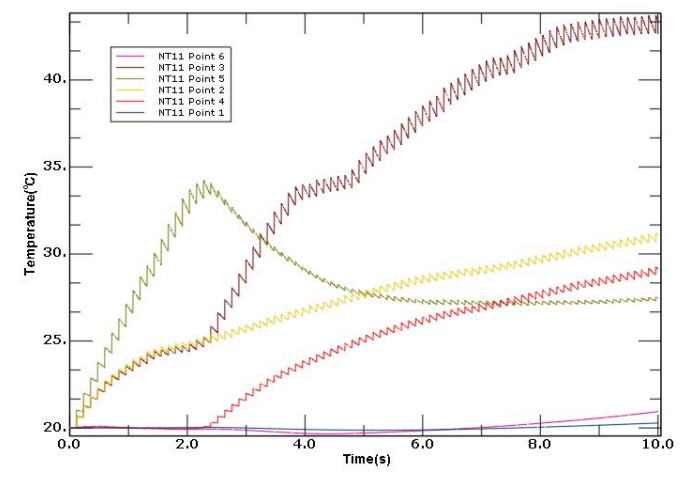

Figure 6. Curves of temperature variation of point1-point6

\section{3) Temperature distribution of peripheral direction of brake} disc

Point 1-4 is taken at friction radius along peripheral direction, as shown in Figure 7. The temperature variation curve is shown in Figure 8.

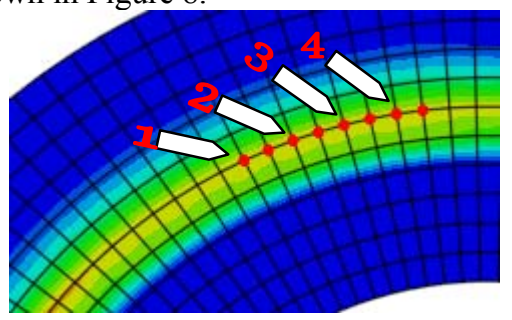

Figure 7. Position of analysis points in brake disc along the circle

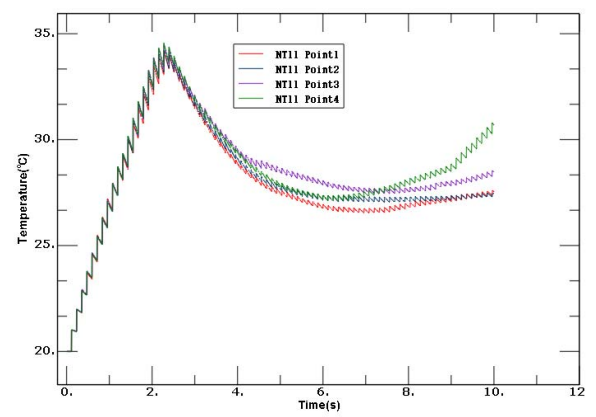

Figure 8. Curves of temperature variation of point1-point4
As you can see from Figure 8: in the condition of same friction radiuses, the temperatures of points $1,2,3$ and 4 display saw-toothed change. Point positions are different, but the friction radiuses are same, so the points go through the same temperature rise and drop process, and the trends are completely same. Each time, the highest temperature rise and lowest temperature rise are approximate, just have different time of reaching extreme are different.

\section{4) Temperature distribution of thickness direction of brake} disc

ZOX plane is used as section vertical to braking plane, so the variation process of temperature distribution along thickness direction of brake disc at different time is obtained, as shown in Figure 9. From the Figure, you can see temperature diffusion from surface to the internal of brake disc.

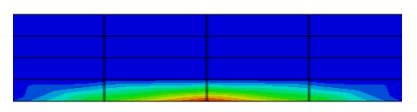

$0.24 \mathrm{~s}$

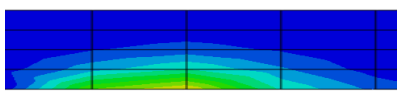

$4 \mathrm{~s}$

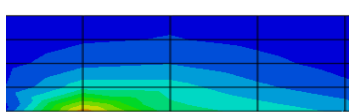

$8 \mathrm{~s}$

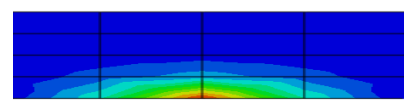

$2 \mathrm{~s}$

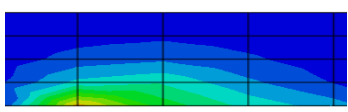

$6 s$

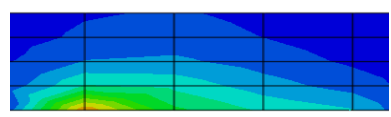

$10 \mathrm{~s}$
Figure 9. Temperature variation in depth direction

Points 1, 2, 3, 4 and 5 are taken along thickness direction of brake disc, as shown in Figure 10. Point 1 is on the friction surface, the distance between point and point is $5 \mathrm{~mm}$, and the temperature variation curve of each point is shown in Figure 11. In the braking process, brake disc is on the depth direction, and temperature variation mainly concentrates on surface friction contact area of brake disc. With extension of the braking time, the temperature gradually diffuses to internal. Because the size of brake disc is far larger than the size of brake pad, the temperature diffusion speed is slow with depth increase.

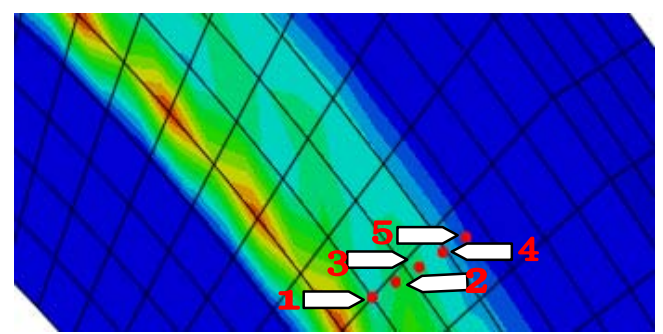

Figure 10. Position of analysis points in brake disc in depth 


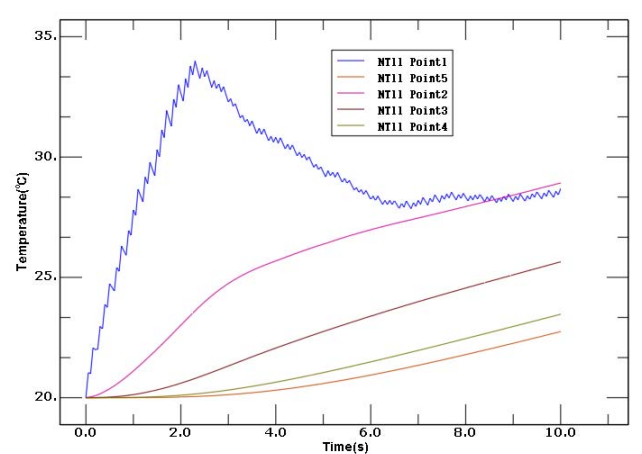

Figure 11. Temperature variation in depth

\section{B. Temperature distribution of brake pad}

Points 1, 2, 3, 4 and 5 are taken in the center axis, as shown in Figure 12. Point 5 is on the contact surface, point 1 is on the upper surface, and the temperature variation curve of these five points is shown in Figure 13.

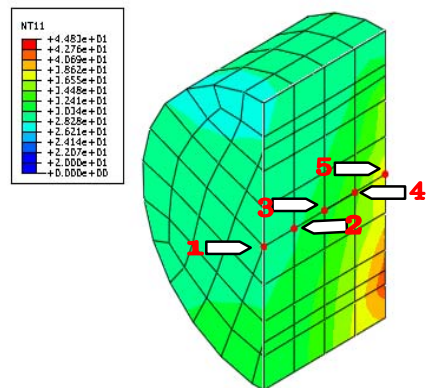

Figure 12. Position of analysis points in brake pad in center

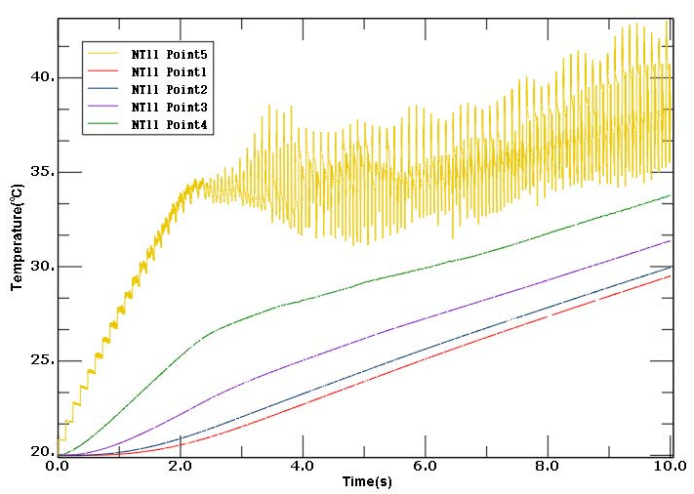

Figure 13. Curves of temperature variation of brake pad

The variation regularity of points $1,2,3$ and 4 are basically same, the temperatures display rise trend, and the temperature variation rates are different at initial stage of braking; about 3 seconds later, regularity of linear variation basically displays, and temperature variation is relatively slow; only if the temperature variation of five points on contact surface is complex, jumping phenomena exist on temperature variation curve, and jumping range is large; that is because complexity of contact is caused, and brake pad is always contacted with brake disc. With elapse of braking time, the size of contact pressure of brake disc and brake pad and the contact position are changed, and temperature at contact place rise quickly; thus, the temperature variation curve of point 5 fluctuates.

\section{SUMMARIES}

1)The heat quantity generated by braking is less and even at initial stage of braking, tailed area using friction radius as center is formed, and the temperature at friction radius is highest; with continuous development of braking process, annular temperature distribution is formed, and surface temperature area of brake disc displays spotted hightemperature; as friction time increases, high-temperature areas are interconnected to form banding distribution.

2)Brake disc is on the depth direction, and temperature variation mainly concentrates on surface friction contact area of brake disc. With extension of the braking time, the temperature gradually diffuses to internal. Because the size of brake disc is far larger than the size of brake pad, the temperature diffusion speed is slow with depth increase.

3)The volume of brake pad is small, and the material of brake pad is heat good conductor using copper as matrix; thus, the temperature of brake pad rises quickly. When braking begins 2.5 seconds, the temperature reaches extreme and its position is on the friction radius, which indicates that the contact performance of brake disc and brake pad is good at initial stage of braking. With extension of braking process, surface temperature begins diffusing to peripheral and thickness directions until it ends.

4)The temperature field distribution obtained by simulation calculation of finite element model provides effective reference for design and engineering application of brake disc and brake pad.

\section{REFERENCES}

[1] Kuncai Qian, Hao Sun. Research on $250 \mathrm{~km} / \mathrm{h}$ high-speed passenger car forging steel brake disc and powder metallurgy brake lining [J]. Locomotive \& Rolling Stock Technology, 2000(2): 30-36.

[2] Jinning Lu, Jianmin Han. Research on $300 \mathrm{~km} / \mathrm{h}$ high-speed train high pure forging steel brake disc material [J]. Journal of the China Railway Society, 2003, 25(6): 10-15

[3] Lele Zhang, Qiang Yang, Nanlin Tan, etc. Analysis of train brake disc transient temperature field based on friction power method $[\mathrm{J}]$. China Railway Science. 2010, 31(1): 99-104

[4] Wenqing Zhao. High-speed train "China Star" brake disc temperature field and thermal stress. Acta Armamentarii [J], 2006, 27(1): 132-136

[5] Haiyan Zhao, Haiquan Zhang, Xiaohua Tang, etc. Finite element analysis of high-speed train disc brake thermal process [J]. Tsinghua Science and Technology (JCR Science Edition). 2005, 45(5): 589-592 